\title{
Improving the Overall Efficiency of Radioisotope Thermoelectric Generators
}

\author{
H.M. Salh \\ Department of Physics, Faculty of Science and Health, Koya University, Erbil, Kurdistan Region of Iraq
}

Copyright $@ 2014$ Horizon Research Publishing All rights reserved.

\begin{abstract}
Radioisotope thermoelectric generators (RTG) convert the decay energy of a radioisotope $\left({ }^{238} \mathrm{Pu}\right)$ into heat then into electricity. RTGs have been used to power space exploration missions. This review paper studies several crucial features of past and present Static RTGs, for instance the advantages of Static RTGs. In addition it reviews Static RTGs limitations such as the shortage in the amount of ${ }^{238} \mathrm{Pu}$ in (U.S.A). Furthermore it compares the future Dynamic RTGs with Static RTGs. It indicates the future Dynamic RTGs, which include a thermodynamic cycle, use 2-4 times less amount of ${ }^{238} \mathrm{Pu}$. In spite of that, their efficiency is almost 4 times greater than past and present RTGs.
\end{abstract}

Keywords Static and Dynamic Radioisotope Thermoelectric Generators, Shortage of ${ }^{238} \mathrm{Pu}$, Efficiency

\section{Introduction}

Radioisotope power production is the process of generating electrical energy from the decay energy of a radioisotope through the use of a radioisotope generator. The most commonly used radioisotopes are the alpha and beta emitters because they do not require the significant shielding as required for gamma emitters. These generators can be divided into two categories which are thermal and non-thermal radioisotope power systems. The non-thermal radioisotope power system outputs are not dependent on temperature differential; they come in many types such as: direct conversion, indirect conversion and direct charge conversion nuclear batteries. Alternatively, the thermal radioisotope power system's outputs are dependent on the temperature gradient between a heat source that includes the radioactive source and a cold side. In addition their outputs are greater than the non-thermal radioisotope outputs. These systems started with general purpose heat source-radioisotope thermoelectric generators (GPHS-RTG) then the multi-mission radioisotope thermoelectric generators (MM-RTG) and the future generation will include the advanced Stirling radioisotope power generators (ASRG). All types of radioisotope power systems have a number of common advantages for instance a long life, high power density and lighter weight compared with other power sources such as solar energy. Also, they still work well in bad weather conditions, various temperatures and pressures, dense atmosphere and vacuums. As a result of this, their applications are becoming wider. Their applications can range from micro-electromechanical systems (MEMS) which need low electrical power such as micro-sensors for measuring and monitoring purposes in the difficult accessible places such as bridges, undersea, building structures, biomedical devices, through to the space exploration missions which require up to a hundred watts during their work on the outer solar systems [1-3].

\section{Static Radioisotope Thermoelectric Generators}

Radioisotope power generators have been employed for space exploration missions; for instance since 1961 more than 27 missions have been powered using over 45 radioisotope thermoelectric generators [3,4]. The first spacecraft, which was launched by National Aeronautics Space Administration (NASA), was transit 4 which used the SNAP-3B (Systems for Nuclear Auxiliary Power) power system. According to [5] the electrical output power for the SNAP-3B was $2.7 \mathrm{~W}$ and the fuel was ${ }^{238} \mathrm{Pu}$. The most recent space mission is the Mars Science Laboratory Rover, launched in 2011. This rover uses multi-mission radioisotope thermoelectric generators to generate approximate $114 \mathrm{~W}$ electricity as the surface operations begin and its fuel is ${ }^{238} \mathrm{Pu}$ [6]. Besides producing the electrical power, these systems provide thermal power which keeps the constituents of the space system warm during their work in extreme and inhospitable environment, e.g. the outer solar systems [7]. Use of radioisotope power systems instead of other power sources has been considered for a variety of reasons. For example $[8,9]$ both highlight the fact that the intensity of sunlight can be either very strong or too low on the outer solar systems. Indeed the intensity of the sun's rays near the surface of the earth is 25 times stronger than those on the surface of Jupiter [10]. They also comment on the difficulty 
of installing generators and replacing component parts within solar systems; solar systems may have a large mass, with a vacuum or dense atmosphere, settling dust, a unique day/night cycles and severe radiation.

\subsection{The Structure of GPHS-RTG}

The static radioisotope thermoelectric power systems consist of three fundamental parts as shown in figure 1 . The first part is the general purpose heat source module GPHS. Each GPHS module has standard dimensions $5.82 \mathrm{~cm}$ height, $9.32 \mathrm{~cm}$ width and $9.96 \mathrm{~cm}$ length, and mass of approximately $1.43 \mathrm{~kg}$ [11]. The aim of this component is to produce the thermal output power of about $250 \mathrm{~W}$ at the beginning of life from the kinetic energy of radioactive decay of the radioisotope ${ }^{238} \mathrm{Pu}$. Each GPHS module is encased with four iridium capsules and a shell of graphite [4]. This is because iridium is ductile and it has good oxidation resistant and chemical compatibility with graphite and ${ }^{238} \mathrm{Pu}$ in the event of accidents and high operating temperatures $[3,11]$. The second part is the thermoelectric convertors (thermocouples) which can be made of different materials such as silicon germanium ( $\mathrm{SiGe})$, telluride of antimony, germanium and silver (TAGS), lead in telluride (PbSnTe) and lead telluride (PbTe). The last mission Mars Science Laboratory Rover uses telluride based thermocouples (PbTe / TAGS) [7,12]. Thermoelectric convertors are connected thermally in a parallel circuit to prevent system failure when a single thermocouple fails and electrically in a series circuit in order to increase the obtained voltage[11]. The third part is the heat sink, which is comprised of radiator fins for example 6063 aluminum fin in multi-mission radioisotope thermoelectric generators[7].

\subsection{The Process of Electrical Power Generation in GPHS-RTG}

According to [13] the process of generating electrical power in such systems depends on the Seebeck effect, which in turn relates to the Peltier and Thomson effects. The Seebeck effect states that the electrical voltage can be generated in a loop, which consists of two different electrical conductive materials with a temperature differential across the junction. This phenomenon was discovered by the German scientist Thomas Seebeck in 1821. The Peltier effect was named after Charles Peltier, who in 1834 found that when an electrical current passes through the same loop, then two different degree of temperature are created in the two dissimilar materials of the loop. The Thomson effect states that depending on the direction of current flowing, the heat is generated in a conductor when electrical current passes through it. This phenomenon was found by the British physicist William Thomson in 1854 [14].

According to [15] the efficiency of a thermoelectric generator depends on a dimensionless parameter known as ZT. This combines both thermal and electrical properties of a thermoelectric generator and is given by:

$$
Z T=\frac{S^{2} \sigma T}{k}
$$

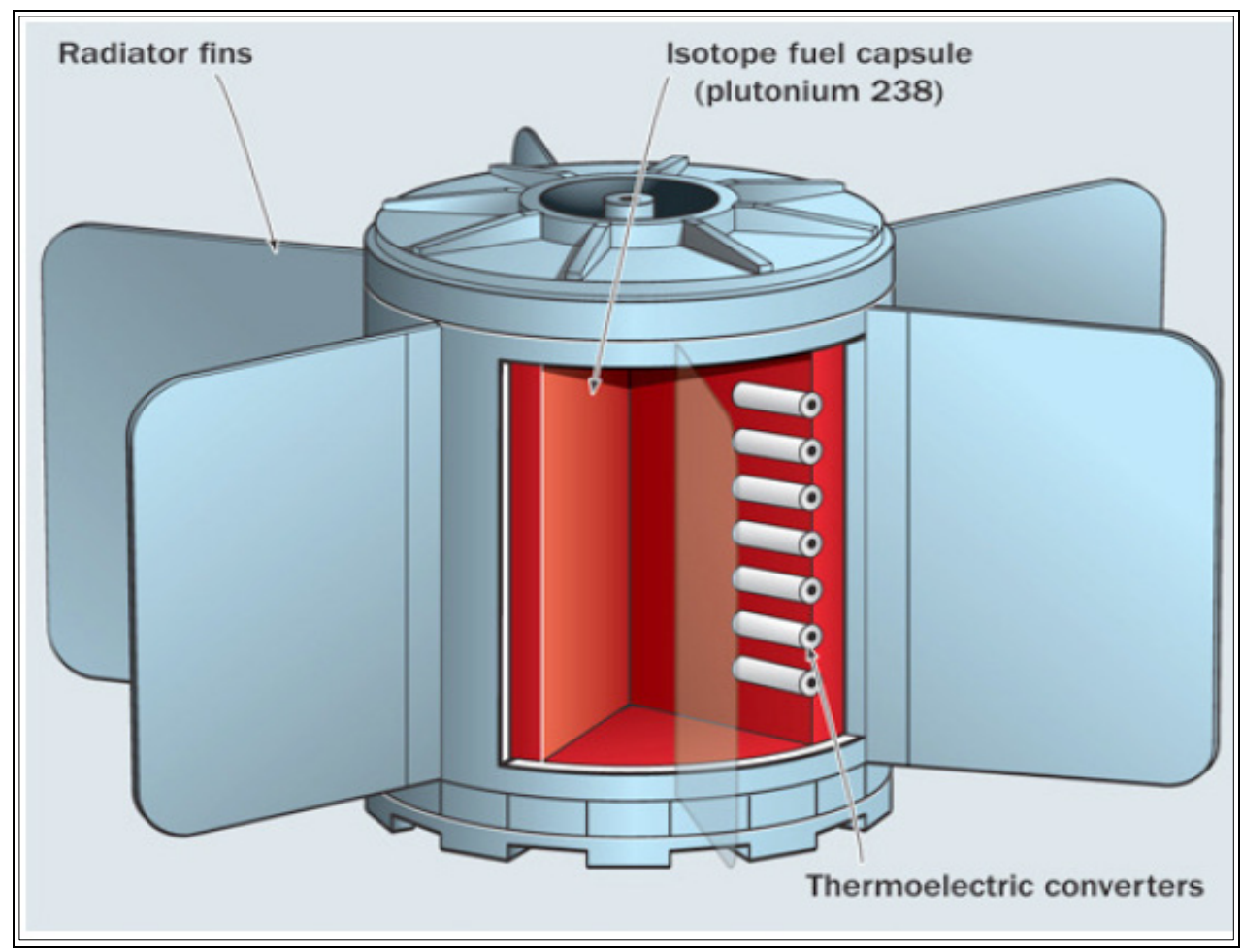

Figure 1. Main components of a radioisotope thermoelectric generator.Taken from [7]. 
Where $S, \sigma, T$ and $k$ represent the Seebeck coefficient, electrical conductivity, absolute temperature and thermal conductivity of the thermoelectric material. The low conversion efficiency of the radioisotope thermoelectric generators around 7\%, [9] may be due to the low ZT values. It has been demonstrated that the $\mathrm{ZT}$ value for $\mathrm{PbTe}$ and $\mathrm{SiGe}$ is about 1 and for TAGS can be about 1.2. It was concluded that if the value of ZT is in between 2-3, then the thermoelectric power is able to compete other power sources. As they have almost the same value of $\mathrm{ZT}$, silicon germanium $(\mathrm{SiGe})$ thermoelectric convertors can be operated over $1000^{\circ} \mathrm{C}$, however the telluride-based materials are limited because their maximum operation temperature is $550^{\circ} \mathrm{C}$ [11]. As shown in equation (1.1) ZT can be developed using a material which has strong electrical conductivity like a crystalline material, and very low thermal conductivity like glass (Weiling and Shantung, 2004). In addition, [15] identified that materials comprising skutterudite crystal are favorable for thermoelectricity process as they have complex structures and covalent bonds, properties which provide lower thermal conductivity and high hole mobility.

\section{3. ${ }^{238}$ Pu Uses in RTG}

As mentioned previously, the isotope which has been most used in such power systems is ${ }^{238} \mathrm{Pu}$. However other isotopes were used in the past, for example polonium ${ }^{210} \mathrm{Po}$ was used by the United Soviet Socialist Republic (USSR) in 1961 and 1971 . Their aim at that time was to generate $800 \mathrm{~W}$ heat in Orion-1 and Orion-2 radioisotope thermoelectric generators (RTGs) respectively [5]. Researchers have been investigating a potential replacement isotope for ${ }^{238} \mathrm{Pu}$. In spite of these efforts, it has been concluded that the most acceptable isotope for space missions is ${ }^{238} \mathrm{Pu}$. There are a number of reasons for this, namely: a long half-life of around 87 years, high power density (heat/ volume), high specific power (heat/ mass) [11] and pure alpha emission (100\% alpha decays) according to [16]. The fuel is formed in a ceramic oxide $\left({ }^{238} \mathrm{PuO}_{2}\right)$ to be used within the GPHS modules because this form has a very high melting point and very low solubility, among other features.

${ }^{238} \mathrm{Pu} \stackrel{\text { alpha decay }}{\longrightarrow}{ }^{234} \mathrm{U}+5.6 \mathrm{MeV}$ (half-life about 87.7 years)

The ${ }^{238} \mathrm{Pu}$ is created when neptunium targets are irradiated by neutrons in a laboratory or by other means.

$$
\left({ }^{237} \mathrm{~Np}+\mathrm{n} \rightarrow{ }^{238} \mathrm{~Np} \stackrel{\beta \text { decay }}{\longrightarrow}{ }^{238} \mathrm{Pu}\right)
$$

Firstly, targets are placed in a nuclear reactor, which utilizes enriched uranium such as light water reactors. During this process sometimes isotope ${ }^{236} \mathrm{Pu}$ is produced as well, which creates difficulties because it emits gamma rays that require significant shielding. Another method that can be used is to reprocess the spent fuels of a nuclear reactor. It can be said that in the United States of America (U.S.A.) production ${ }^{237} \mathrm{~Np}$ targets are limited as they occur either naturally in uranium ores in very low (trace) amounts, or they can be created artificially. But it must be acknowledged that these processes mentioned above need significant amounts of money, time, workers, etc [3]. While the RTGs are reliable and generate enough power for space application missions by NASA, there is an issue concerning the shortage of the ${ }^{238} \mathrm{Pu}$ in the U.S.A. [16] warned that "the isotope ${ }^{238} \mathrm{Pu}$ is no longer available for use as a power source for NASA space probes, and an alternative must be found."

\subsection{Solutions to Shortage ${ }^{238} \mathrm{Pu}$}

Researchers and specialists have been investigating different approaches to overcome this shortage. First they have been attempting to reduce the total amount of the ${ }^{238} \mathrm{Pu}$ required by reducing the number of GPHS modules used within these power systems. This solution can be achieved by using materials that are more efficient and incorporating solar arrays beside RTGs for suitable outer solar systems. The earlier GPHS- RTGs utilized 18 GPHS modules with the total $7.6 \mathrm{~kg}$ of ${ }^{238} \mathrm{Pu}$, this has been reduced to $3.5 \mathrm{~kg}$ for the new multi-mission RTGs, because they use just 8 GPHS modules $[8,12]$. Other vital differences between past, present and future radioisotope power systems in NASA missions can be seen in the table 1. Another solution could be that research must be carried out in order to find out the most suitable radioisotope to replace ${ }^{238} \mathrm{Pu}$. When [16] investigated seven radioisotopes ${ }^{209} \mathrm{Po},{ }^{232} \mathrm{U},{ }^{243} \mathrm{Cm},{ }^{244} \mathrm{Cm},{ }^{249} \mathrm{Cf},{ }^{250} \mathrm{Cf}$ and ${ }^{251} \mathrm{Cf}$, he noticed that smaller masses of ${ }^{250} \mathrm{Cf},{ }^{244} \mathrm{Cm}$, and ${ }^{243} \mathrm{Cmcan}$ generate more power than ${ }^{238} \mathrm{Pu}$, and these isotopes met the safety criteria. However, the most suitable isotope is ${ }^{250} \mathrm{Cf}$ because according to [16] it has higher specific power than ${ }^{238} \mathrm{Pu}$. The final solution, which NASA has worked on, is the use of dynamic radioisotope power systems. One type of dynamic power systems is the advanced Stirling radioisotope generator, which will be explained in the next section.

Table 1. The key differences between the past (GHPS-RTG), present (MMRTG) and future (ASRTG). Taken from [3]

\begin{tabular}{|c|c|c|c|}
\hline & GPHS-RTG & MMRTG & ASRG \\
\hline Electric output,BOM,We & 285 & 125 & $\approx 150$ \\
\hline Heat input, BOM, We & 4500 & 2000 & 500 \\
\hline $\begin{array}{c}\text { RPS system efficiency, } \\
\text { BOM, \% }\end{array}$ & 6.3 & 6.3 & 30 \\
\hline Total system weight, kg & 56 & 44.2 & $\approx 21$ \\
\hline Specific power, We/kg & 5.1 & 2.8 & 8 \\
\hline $\begin{array}{c}\text { Number of GPHS } \\
\text { modules }\end{array}$ & 18 & 8 & 2 \\
\hline GPHS module weight, kg & 25.7 & 12.9 & 3.2 \\
\hline Pu-238 weight, kg & 7.6 & 3.5 & 0.88 \\
\hline
\end{tabular}

\section{Dynamic Radioisotope Thermoelectric Generators}

As discussed in the previous section, the previous large-scale radioisotope power generators by NASA have suffered from three main limitations which are summarized 
as, a shortage and limited availability of ${ }^{238} \mathrm{Pu}$, low conversion efficiencies of about $6 \%$ and limited application in vacuum environments with past GPHS -RTGs [8] In order to overcome these limitations interesting and significant work has been done in the field of dynamic radioisotope power systems. They are called dynamic systems because they include at least one moving component. Dynamic systems include free-piston Stirling, closed Brayton and Rankine cycles [11]. This paper focuses on Stirling systems.

\subsection{Advanced Stirling Radioisotope Power Systems}

The advanced Stirling radioisotope power systems for space applications converts the decay kinetic energy into mechanical and then into electrical energy. It consists of two generators originally placed in opposition to each other in order to preserve the balance of the system. However, [18] demonstrated that it would be better, if the generators were placed vertically because this would minimize the dust accumulation on the surface of the heat rejecter component during their use in the environment of Mars. Each generator consists of many components, but the fundamental parts are as follows: a GPHS module; a heater head that is made of a nickel composed alloy such as Inconel 718; (i.e. materials with a suitable creep life and thermodynamic performance), the heater head like a pressure vessel, where the heat from the GPHS module is either supplied to the thermodynamic cycle; the third crucial composition is an inert working gas such as helium; the fourth part is a power piston; the fifth part consists of two permanent magnet layers, for instance neodymium iron boron $(\mathrm{FeNdB})$ magnets [19,20].

The process of generating electricity in an advanced Stirling radioisotope power generator starts by producing heat in the GPHS module from decay of ${ }^{238} \mathrm{Pu}$. After that, the created heat is supplied to the working gas (helium) in the heater head, as a result the gas expands and then the heat is rejected by the rejecter and due to this change of gas temperature, an immediate change in the pressure of the working gas occurs. As a consequence of this the power piston is moved back and forth inside the magnets. Eventually this linear motion is converted into AC electrical power, and then to DC electrical power using power management circuits $[11,20]$.

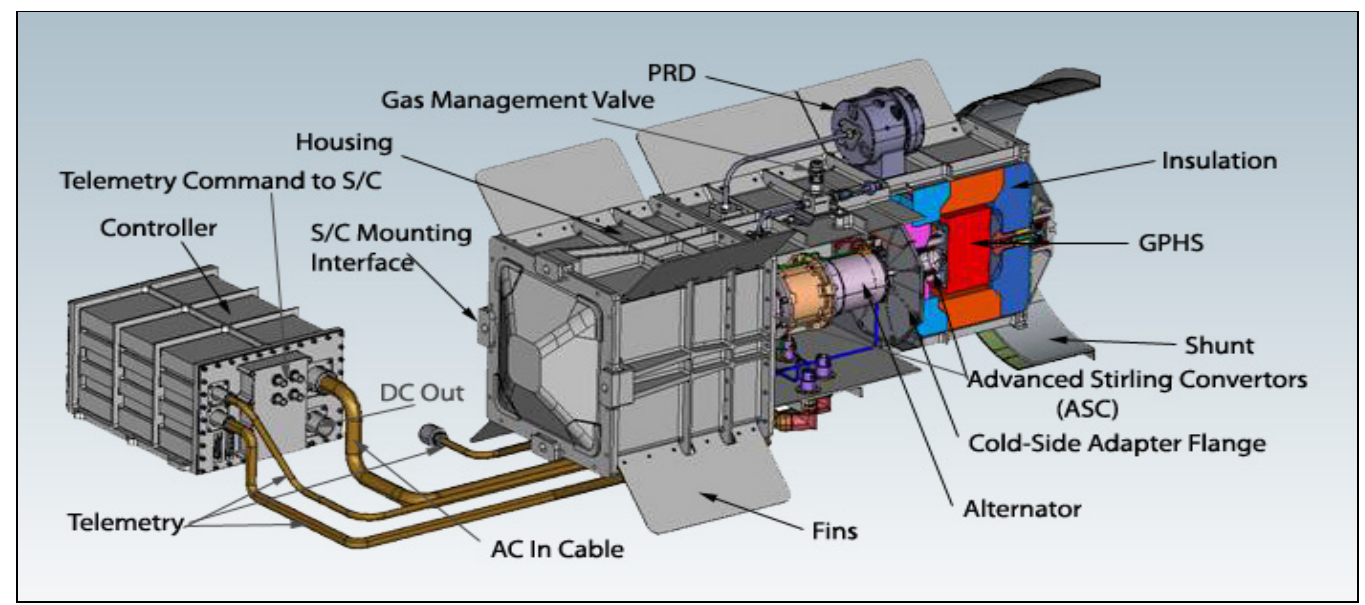

Figure 2. An advanced Stirling radioisotope power system. Taken from [17]

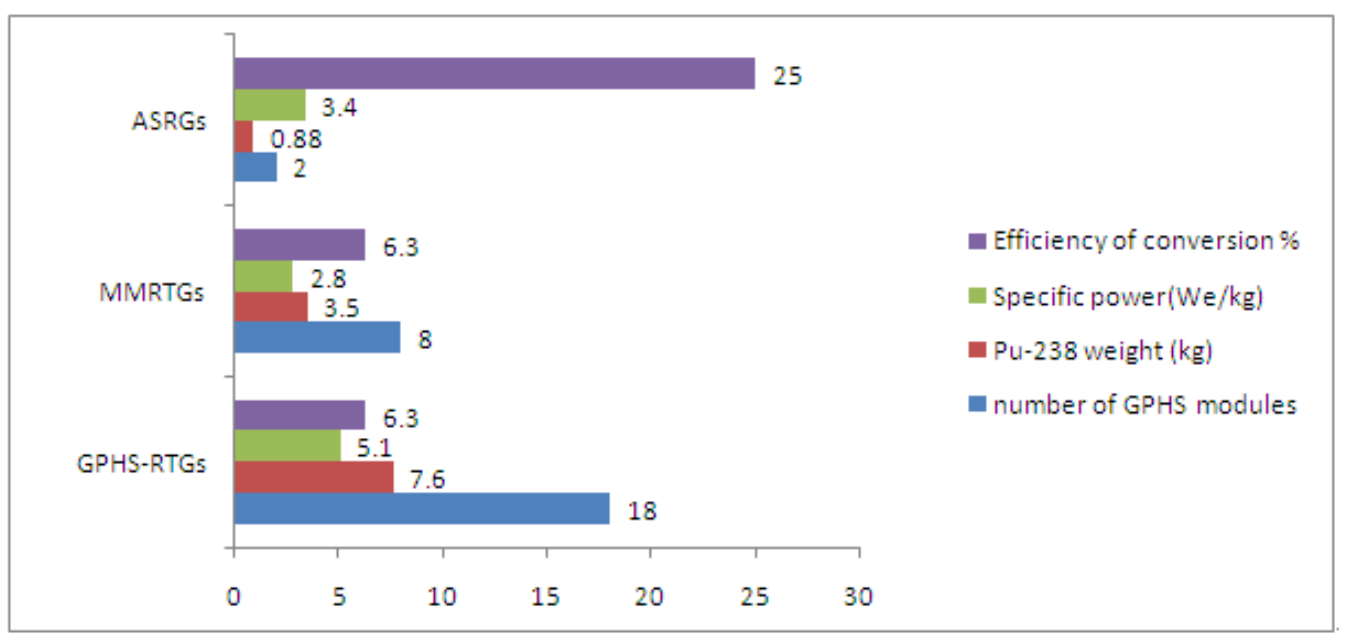

Figure 3. Comparison between GPHS-RTG, MMRTG and ASRG in terms of the number of GPHS modules, weight of used 238Pu, the specific power and efficiency of conversion. Information taken from $[3,8]$ 


\subsection{Advantages and limitations of ASRGs}

There are many advantages to advanced Stirling radioisotope power generators (ASRGs) in comparison with past GPHS-RTGs and MMRTGs as shown previously in table 1. For instance: Stirling power systems have a higher conversion efficiency of around $25 \%$, which is almost 4 times greater than for both GPHS-RTGs and MMRTGs but they use the same power source ${ }^{238} \mathrm{Pu}$. On the other hand, the specific power of ASRGs is about $3.4 \mathrm{We} \cdot \mathrm{kg}^{-1}$, but the specific power of MMRTG is about $2.8 \mathrm{We} \cdot \mathrm{kg}^{-1}$. This aspect plays a crucial role in minimizing the dimensions of the generator. It is aimed to produce $147 \mathrm{We}$ at the beginning of mission by using just two GPHS modules. Therefore the required amount of ${ }^{238} \mathrm{Pu}$ is $0.88 \mathrm{~kg}$; this amount is $3.5 \mathrm{~kg}$ for MMRTGs and 7.6kg for GPHS-RTGs by using 8 and 18 GPHS modules respectively. This reduction indicates that the total amount of used ${ }^{238} \mathrm{Pu}$ is 2-4 times less than those for both GPHS-RTGs and MMRTGs. Key differences are illustrated in figure 3. Secondly, ASRGs can have a good electrical output power even though the temperature gradient between the heater head-side and the cold-side is small. This eliminates the need to use advanced alloys. Instead, lightweight materials such as titanium, stainless steel or aluminum can be used in the construction process. A third advantage is that SRPS is a multi-purpose system, which can work on the outer solar systems with either a dense atmosphere such as Mars and Titan, or a vacuum $[8,20]$. In addition, the ASRGs has advantages compared with other dynamic systems, for example it uses a single phase working gas while Rankine cycles consume two- phase working fluid. Secondly the ASRG does not include compressors, pumps and turbines such as Brayton and Rankine cycles. Furthermore, Brayton and Rankine need an external power to start up their operation but it is not required for ASRGs [11].

In spite of advantages such as reliability, capability, longlife and scalability, ASRGs have some limitations. For example the life-time may be shortened by the life-time of the permanent magnets, the heater head and other apparatuses [19]; there is a small chance to contamination and corrosion as they use an inert gas working fluid [20] and in the case of sending them to Mars environment, the $\mathrm{CO}_{2}$ of Mars's atmosphere can react with the graphite shell of the GPHS modules and this can result in the mass loss of the graphite shell, also moving parts can easily fail [18]

\section{Conclusions}

It was observed that the safety criteria, long-life, high specific power and power density and high melting of ${ }^{238} \mathrm{Pu}$ were the main reasons behind choosing it for the past, present and future thermal radioisotope power generators. The efficiency of radioisotope thermoelectric generators (GPHS-RTG and MM-RTG) depends on the thermal and electrical conductivity of thermocouples, and the temperature difference between the hot and cold sides, but it may limit improvements to very high efficiencies. Because the melting point of the generator components would not be able to withstand this high temperature. Therefore an idea emerged to include a thermodynamic cycle in such generators such as Stirling engine cycle. Significant success, in terms of efficiency and the amount of used ${ }^{238} \mathrm{Pu}$ have been achieved with these new systems.

\section{REFERENCES}

[1] Bower, K. E. et al. (2002) Polymers, phosphors, and voltaics for radioisotope microbatteries. Florida: CRC Press LLC.

[2] Huffman, F. N. and et al (1974) Radioisotope powered cardiac pacemakers. Nuclear Science, IEEE Transactions on 21, no. 1 (1974):pp. 707-713.

[3] National Research Council, (2009) Radioisotope Power Systems: An imperative for maintaining US leadership in Space Exploration. Washington, D.C. The National Academies Press.

[4] Cataldo, R. L., Colozza, A. J. and Schmitz, P. C. (2013) Potential Applications for Radioisotope Power Systems in support of Human Exploration Missions. Proceedings of Nuclear and Emerging Technologies for Space 2013, Albuquerque, NM, February 25-28, 2013.

[5] Pustovalov, A. A. (1997) Nuclear Thermoelectric Power Units in Russia, USA and European Space Agency Research Programs in 16th International Conference on Thermoelectrics, 1997.

[6] Jones, L., Moreno, V. and Zimmerman, R. (2013) The F1 Multi-Mission Radioisotope Thermoelectric Generator (MMRTG): A Power Subsystem Enabler for the Mars Science Laboratory (MSL) Mission. Proceedings of Nuclear and Emerging Technologies for Space 2013, Albuquerque, NM, February 25-28, 2013.

[7] Cataldo, R. L. and Bennett, G. L. (2011) U.S. Space Radioisotope Power Systems and Applications: Past, Present and Future.NASA Glenn Research Center and Metaspace Enterprises, USA.

[8] Anderson, D. J. et al. (2007) NASA's Advanced Radioisotope Power Conversion Technology Development Status. IEEEAC paper 1610.

[9] Wong, W. A. (2004) Advanced Radioisotope Power Conversion Technology Research and Development. Glenn Research Center.AIAA-2004-5515.

[10] Weiling, L. and Shantung, T. (2004) Recent Developments of Thermoelectric Power Generation. Chinese Science Bulletin 49 No. 12 June 2004.

[11] Lange, R. G. and Carroll, W. P. (2008) Review of Recent Advances of Radioisotope Power systems. Energy Conversion and Management 49 (2008) 393-401.

[12] Ritz, F. and Peterson, C. E. (2004) Multi-Mission Radioisotope Thermoelectric Generator (MMRTG) Program Overview.2004 IEEE Aerospace Conference Proceedings.

[13] El-Wakil, M. M. (1971). Nuclear energy conversion. 
[14] Pollock, D. D. (1985) Thermoelectricity: Theory, Thermometry, Tool. American Society for Testing and Materials 1985.

[15] Fleurial, J. P. et al. (1997) High Performance Thermoelectric Materials and Methods of Preparation. United States Patent, Patent number 5,610,366.

[16] Nadeau, M. (2012) Replacing Plutonium-238 in Radioisotope Power Systems (online). Available from: http://aladinrc.wrlc.org/handle/1961/10657 [accessed on 3 July 2013].

[17] National Aeronautics Space Administration (2013) Advanced Stirling Radioisotope Generator (ASRG) The Next Generation Radioisotope Power System (online). Available from: http://solarsystem.nasa.gov/rps/asrg.cfm[ accessed on 3 September 2013].

[18] Cockfield, R. D. and Chan, T. S. (2002) Stirling Radioisotope Generator for Mars Surface and deep Space Missions. 37th IECEC 2002, Paper No: 20188.

[19] Mason, L. S. and Schreiber, J. G. (2007) A Historical Review of Brayton and Stirling Power Conversion Technologies for Space Applications. NASA/TM-2007-214976, paper 2034.

[20] Schreiber, J. G. (2006, June). Developmental Considerations on the Free-Piston Stirling Power Convertor for Use in Space. In Proceedings of the 4th International Energy Conversion Engineering Conference (IECEC-2006), San Diego, CA. 